Chapman University

Chapman University Digital Commons

$10-11-2014$

Studying Teacher Noticing: Examining the Relationship Among

Pre-service Science Teachers' Ability to Attend, Analyze and

Respond to Student Thinking

Tara Barnhart

Elizabeth van Es

Follow this and additional works at: https://digitalcommons.chapman.edu/education_articles

Part of the Educational Assessment, Evaluation, and Research Commons, and the Science and Mathematics Education Commons 


\section{Studying Teacher Noticing: Examining the Relationship Among Pre-service Science Teachers' Ability to Attend, Analyze and Respond to Student Thinking}

\section{Comments}

NOTICE: this is the author's version of a work that was accepted for publication in Teaching and Teacher Education. Changes resulting from the publishing process, such as peer review, editing, corrections, structural formatting, and other quality control mechanisms may not be reflected in this document. Changes may have been made to this work since it was submitted for publication. A definitive version was subsequently published in Teaching and Teacher Education, volume 45, in 2015. https://doi.org/ 10.1016/j.tate.2014.09.005

The Creative Commons license below applies only to this version of the article.

\section{Creative Commons License}

\section{(c) $† \odot \ominus$}

This work is licensed under a Creative Commons Attribution-Noncommercial-No Derivative Works 4.0 License.

\section{Copyright}

Elsevier 
Studying teacher noticing: Examining the relationship between pre-service science teachers' ability to attend, analyze and respond to student thinking

\author{
Tara Barnhart \\ School of Education \\ University of California, Irvine \\ 3200 Education \\ Irvine, CA 92697-5500, USA \\ $1-562-708-9703$ \\ tbarnhar@uci.edu \\ Elizabeth van Es \\ School of Education \\ University of California, Irvine \\ 3455 Education \\ Irvine, CA 92697-5500, USA \\ $1-949-824-7819$ \\ evanes@uci.edu
}

This research was supported in part by the Knowles Science Teaching Foundation. The opinions expressed are those of the authors and do not necessarily reflect the opinions of the supporting agency. 
DEVELPOING PSTS' ABILITY TO ATTEND, ANALYZE, AND RESPOND

\begin{abstract}
This study investigates pre-service teachers' capacities to attend to, analyze, and respond to student thinking. Using a performance assessment of teacher competence, we compare two cohorts of science teacher candidates, one that participated in a video-based course designed to develop these skills and one that did not. Course participants demonstrate more sophisticated levels of attention to and analysis of student ideas. Analysis of the relationship between skills reveals that sophisticated analyses and responses to student ideas require high sophistication in attending to student ideas. However, high sophistication in attending to student ideas does not guarantee more sophisticated analyses or responses.

Keywords: Reflective teaching, Student teaching, Student teachers, Secondary school science, Teacher noticing, Pre-service teacher education
\end{abstract}


DEVELPOING PSTS' ABILITY TO ATTEND, ANALYZE, AND RESPOND

\section{Introduction}

Few factors have a greater impact on student learning than the quality of his or her teacher (Darling-Hammond, 2010; Strauss \& Sawyer, 1986; Whitehurst, 2002). While there is disagreement about what specific skills or dispositions make one teacher more effective than another (Goldhaber \& Anthony, 2004), there is consensus around the importance of teachers being able to problematize and critically analyze their practice (Little \& Horn, 2007; Windschitl, Thompson, \& Braaten, 2011). Teachers who have opportunities to rigorously reflect on their work and connect it to research and theory during their professional preparation are better able to identify and respond to dilemmas of practice, are more likely to take an analytic stance toward their work, and are more likely to demonstrate a willingness to take risks and explore alternative pedagogical approaches (Darling-Hammond \& Bransford, 2005; Davis, Petish, \& Smithey, 2006; Zeichner \& Liston, 1996). Moreover, research on teacher expertise shows that expert teachers can distinguish between important and unimportant information in a complex situation, can reason about what they observe and can use this analysis to make more informed teaching decisions (Berliner, 2001).

Despite its value, building reflective and analytic skills can be challenging. This is particularly true in the context of pre-service teacher education. The fieldwork sites may not promote systematic and rigorous analysis; the preconceptions pre-service teachers bring into the profession can interfere with what they choose to reflect on and how they reason about the effectiveness of their teaching; and pre-service teachers may lack the observation skills and pedagogical content knowledge required for sophisticated analyses of teaching and learning (Borko \& Livingston, 1989; Hammerness, Darling-Hammond, \& Bransford, 2005; Hiebert, Morris, Berk, \& Jansen, 2007; Richardson, 1998; Schoenfeld, 2011; Star \& Strickland, 2008). 
DEVELPOING PSTS' ABILITY TO ATTEND, ANALYZE, AND RESPOND

A further complication is that simply adding requirements to teacher education programs to analyze practice, be it through coursework assignments or high-stakes portfolio assessments such as California's Teacher Performance Assessment, without providing guidance in what should be analyzed, for what purpose, and how, results in superficial learning and may even be mis-educative (Dewey, 1933; Loughran, 2002; Zeichner \& Liston, 1996). This is because, without structured support and appropriate framing, pre-service teachers' analyses tend to focus on the actions and behaviors of the teacher rather than student thinking, learning and sensemaking (Hammer, 2000; Levin, Hammer, \& Coffey, 2009). Additionally, the arguments preservice teachers construct about teaching tend to be judgmental and lack evidential support and coherence (Davis, 2006; Sandoval, Deneroff, \& Franke, 2002). Research proposes that preservice teacher education is a critical time to develop beginning teachers' reflective skills (Feiman-Nemser, 2001; Hiebert et al., 2007) because teachers cannot learn all they need to know to become an effective teacher in the brevity of teacher education programs.

The purpose of this study is to investigate how a video-based course, Learning to Learn from Teaching (Santagata \& van Es, 2010), supported secondary science pre-service teachers in learning to analyze and reflect on teaching and learning in systematic ways. A central component of the course was learning to use evidence of student thinking as it unfolds in the lesson to draw inferences about the effectiveness of instruction and using this analysis to make subsequent pedagogical decisions. This type of analysis requires that pre-service teachers: a) attend to student thinking and learning and the interactions that unfold between students and between teachers and students, b) interpret student understanding from these interactions, and c) decide next steps based on this analysis. Recent research refers to this collection of skills as teacher noticing (Jacobs, Lamb, \& Philipp, 2010). Of particular interest in this study is the relationship 
DEVELPOING PSTS' ABILITY TO ATTEND, ANALYZE, AND RESPOND

between these skills. To date, several researchers have investigated these skills in isolation, with some researchers focusing on pre-service teachers' abilities to articulate clear learning goals (Jansen, Bartell \& Berk, 2009; Morris, Hiebert, \& Spitzer, 2009), others on their ability to attend to student thinking and learning in a lesson (Levin, Hammer, \& Coffey, 2009; Nicol \& Crespo, 2004; Ruiz-Primo \& Furtak, 2007; Star \& Strickland, 2008; van Es \& Sherin, 2002; van Zee \& Minstrell, 1997), and others on the use of evidence to support claims of teaching effectiveness (Morris, 2006; Santagata \& Yeh, 2013; Stockero, 2008). Less attention has been paid, however, to how development of one skill influences development of the others and how they coordinate to construct a coherent analysis of teaching practice. An empirical investigation into this relationship will advance research on the construct of noticing and has implications for the design of teacher education.

While research suggests that pre-service teachers can develop analytic skills in the context of a course where they analyze their own and other's teaching (Pang, 2011; Santagata \& Angelici, 2010), few studies have examined whether they draw on these skills when they analyze their own teaching after the conclusion of the course. Thus, the central research questions for this study include: a.) Do pre-service teachers who participated in a course designed to scaffold systematic analysis of teaching through video analysis draw on the skills to analyze their own teaching compared to a cohort of teachers who did not participate in the course? b.) How are the skills of systematic analysis of teaching related to each other? To investigate these questions, we compare a cohort of secondary science teacher candidates that participated in the Learning to Learn from Teaching (LLfT) course to one that did not. We begin by discussing the theoretical framing of our study. Then, we describe the video-based course in greater detail followed by the research study design and the results. We conclude by addressing the implications of the findings 
DEVELPOING PSTS' ABILITY TO ATTEND, ANALYZE, AND RESPOND

for understanding pre-service teacher analysis and reflection and for the design of teacher education.

These questions are particularly relevant in science education internationally. In the US, proposals for the improvement of science teaching and learning emphasize teaching students how to collect, interpret, and evaluate evidence to formulate scientific explanations of observed phenomena (American Association for the Advancement of Science [AAAS], 2009; National Research Council [NRC], 2007, 2012; Sandoval, Deneroff, \& Franke, 2002; Windschitl, Thompson, \& Braaten, 2008, 2011). This is also the case in other countries where science curricula emphasize the importance of developing scientifically literate citizens and is reflected in the highest proficiency levels on the PISA (OECD, 2013; Waddington, Nentwig \& Schanze, 2007). Because the scientific body of knowledge is in constant flux with increasing amounts of information being added or modified (Gleick, 2011), students must be able to ask critical questions and possess appropriate skepticism about proposed explanations and interpretations of scientific phenomena. Moreover, they need to successfully navigate the flood of information to participate knowledgeably in public discussions about science and technology and be sensible consumers of information about science and related issues (NRC, 2012). Thus, learning science is not only about knowing science content, but it also involves attending to and reasoning about scientific ideas, generating and testing models of scientific phenomena, and being effective problem solvers (AAAS, 2009; Levin, Hammer, \& Coffey, 2009; Ministry of EducationSingapore, 2013; NRC 2012). To achieve this vision of science education requires that preservice teachers develop strategies for systematically analyzing their ability to build students' scientific reasoning skills and for assessing students' progress in achieving these goals.

\section{Theoretical Framework}


DEVELPOING PSTS' ABILITY TO ATTEND, ANALYZE, AND RESPOND

\subsection{The Importance of Reflection and Analysis for Learning to Teach}

This study is framed by research on reflection, teacher noticing and lesson analysis.

Dewey (1933) and Schön (1983) each made important contributions to the field by defining the phases and mind-set needed for critical reflection. Each believed reflective practitioners should be engaged in ongoing, systematic, rigorous, and disciplined meaning-making with the aim of improving practice. They identify effective reflection as an analytic approach to problem-solving distinct from informal ways of thinking about teaching and instruction in which teachers direct their attention to particular details of practice, make sense or give reason to these details, and use their analysis of these details to develop hypotheses about how to solve dilemmas of classroom practice. In this way, teachers become skilled professionals rather than mindless technicians who simply consume and implement instruction designed by others.

An important characteristic of these reflective models is the use evidence from teaching to inform practical theories to test in practice. In Dewey's (1933) perspective, all rigorous reflection is grounded in experience. When an experience is perceived as a basis upon which to build future decisions, it becomes evidence. Similarly, Schön (1983) writes that professionals bring past experience to bear on new situations and problems, allowing them to use experience as evidence to form new theories for future action.

However, research on teacher noticing (Erickson, 2011) suggests that what teachers choose to attend to and use as evidence from their experiences may not provide them with the kind of information they need to draw accurate inferences about student learning. Novice teachers typically focus on superficial features of classroom interactions or use student behaviors, such as raising hands enthusiastically, staying on-task, and following classroom norms and routines in an orderly fashion to deduce that students understood the lesson (Carter, 
DEVELPOING PSTS' ABILITY TO ATTEND, ANALYZE, AND RESPOND

Cushing, Sabers, Stein, \& Berliner, 1988; Copeland, Birmingham, DeMeulle, D’Emidio-Caston, \& Natal, 1994; So, 2012; Star \& Strickland, 2008; Star, Lynch, \& Perova, 2011). Erickson (2011) also found that novice teachers focused on the learning of the whole class, rather than attending to unique student ideas, making sense of those ideas, and understanding how they fit into achieving the broader learning goal. This results in overgeneralizations about student learning, leaving teachers with an inaccurate sense of the effectiveness of the lesson (Lloyd, Mukhergee, 2012; Loughran, 2002; van Es \& Sherin, 2002; van Manen, 1977).

Simply encouraging pre-service teachers to pay attention to details of practice is not sufficient to improve practice. Zeichner and Liston (1987), and more recently Levin and colleagues (2009) contend that a key characteristic of effective reflection is how teachers frame problems of practice because this influences what details teachers' then identify as worthy of attention and how these details will be analyzed and used to construct testable theories about practice. This suggests then that pre-service teachers need to be provided with tools and frameworks to help guide what they attend to in teaching, how they interpret these events, and how they draw inferences from these experiences to make informed teaching decisions. Providing an organizational frame permits more sophisticated attention to salient details and enables the transformation of these noticed details into evidence that can be used to inform future instructional decisions.

\subsection{Learning to Systematically Analyze Teaching}

Recent research proposes frameworks to support pre-service and practicing teachers in developing productive approaches for analyzing teaching (Ermeling, 2010; Hiebert et al., 2007; Rodgers, 2006; Santagata \& Angelici, 2010). Consistent across these models is a focus on defining a clear learning goal, using evidence from practice - such as, student work or video of 
DEVELPOING PSTS' ABILITY TO ATTEND, ANALYZE, AND RESPOND

classroom interactions - to inform analysis, and examining the cause-effect relationship between particular teaching practices and student learning. Teaching is framed then as an experiment with the teacher engaged in a methodical approach to examine and learn from practice (Spitzer, Phelps, Beyers, Johnson, \& Sieminski, 2011).

We propose that to engage in this kind of systematic analysis requires development of a variety of skills, including attending to what is noteworthy in classroom data, analyzing and interpreting that data with respect to defined goals, and deciding how to respond, what research refers to as teacher noticing (Jacobs, Lamb, \& Philipp, 2010; Star \& Strickland, 2008; van Es \& Sherin, 2002). While pre-service teachers tend to focus their attention on classroom management and tasks, research shows that with structured guidance, they can become better attuned to and inferential about the relationship between teaching and learning (Star, Lynch, \& Perova, 2011; van Es \& Sherin, 2002). Other researchers emphasize the importance of using analysis to make evidence-based decisions on how to respond to students' thinking, noting that it can improve with experience and practice (Hiebert et al., 2007; Jacobs, Lamb and Philipp, 2010; Santagata \& Angelici, 2010; Stürmer, Könings, \& Seidel, 2012).

Studies of teacher noticing, lesson analysis, and reflection often conceptualize a connection between the elements on attending, analyzing, and responding. For example, in Davis's (2006) research on productive reflection she examined what aspects of teaching preservice teachers consider, emphasize and integrate when they reflect on their science teaching. In her study, a more integrated reflection was one that made connections between aspects of teaching pre-service teachers noticed. Similarly, Jacobs and colleagues "envision the existence of a nested relationship among the three component skills such that deciding how to respond on the basis of children's understandings can occur only if teachers interpret children's understanding, 
DEVELPOING PSTS' ABILITY TO ATTEND, ANALYZE, AND RESPOND

and these interpretations can be made only if teachers attend to the details of children's strategies” (p. 197). Research on lesson analysis also implies a relationship between these skills by examining how pre-service teachers learn to collect and use evidence to determine the impact of teachers' instruction on student learning (Morris, 2006). One important contribution of this body of work is that it identifies the necessary sub-skills for reflection and analysis (Santagata, 2011) and explores how they improve over time (Star, Lynch, \& Perova, 2011; van Es \& Sherin, 2002). What is less clear, however, is how they are connected and how developing on one skill may or may not relate to developing on another. The purpose of this paper is to empirically investigate the relationship between these sub-skills. First, we examine if secondary science preservice teachers draw on analytic skills they develop in a video-based course designed to facilitate systematic analysis of teaching several months after the conclusion of the course. We compare their responses on the Performance Assessment for California Teachers (PACT) to those of a cohort of secondary science pre-service teachers who did not participate in the intervention course. We also examine the relationships between each of the sub-skills to gain insight into how they influence each other. Such an analysis will provide greater insight into the construct of teacher noticing, as well as inform pre-service teacher educators' efforts to design instruction to help pre-service teachers develop their ability to systematically analyze and reflect on teaching.

\section{Research Design}

\subsection{Study Context}

Participants in this study are secondary science pre-service teachers in a nine-month, three quarter credential program at a large, public university in California. Candidates complete supervised fieldwork each quarter, primarily observing a master teacher in the first quarter and eventually taking on full responsibility of the class as a student teacher by the beginning of the 
DEVELPOING PSTS' ABILITY TO ATTEND, ANALYZE, AND RESPOND

third quarter. They also enroll in a variety of courses related to content area methods, general pedagogy, learning theory, language and literacy in the content areas, and equity and diversity. All students seeking a secondary teaching credential enrolled in the Learning to Learn from Teaching (LLfT) course in the first quarter of the program during the year of this study. Because the students spend an extensive amount of time in the field observing teaching, the course was designed to support them in learning to develop their observation skills of teaching. The course draws extensively on what is known about best practices using video cases and structured frameworks to scaffold and apprentice pre-service teachers into reflective work in authentic practice-based context (Hiebert, et al., 2007; Rodgers, 2002b; van Es \& Sherin, 2002). In particular, the course intends to develop pre-service teachers' skills in three domains: attention to student thinking; interpretation of student thinking; and planning and enactment of strategies to make student thinking visible (Santagata \& van Es, 2010). This course makes extensive use of video cases to help pre-service teachers learn to analyze teaching by focusing on the connections between teaching and learning and using evidence of student thinking and learning to guide instructional decision-making.

The course consists of three main phases (Santagata \& van Es, 2010). The first phase introduces students to theories about analytic and responsive teaching practice. The second phase focuses on providing structured practice using frameworks such as those proposed by Hiebert and colleagues (2007) and Rodgers (2002b) to analyze student thinking represented in the videos, as well as to examine strategies that teachers in the videos employed to promote classroom discourse to make student thinking visible (Blythe, 1997; Hufferd-Ackles, Fuson, \& Sherin, 2004; Lemke, 2002; van Zee \& Minstrell, 1997). In the final phase, students apply these skills to design, video record, and reflect on their own teaching practice. 
DEVELPOING PSTS' ABILITY TO ATTEND, ANALYZE, AND RESPOND

\subsection{Data}

Data for the study consists of responses to the Performance Assessment for California Teachers (PACT) for two cohorts of pre-service science teachers: one cohort that participated in the LLfT course $(n=16)$ and one cohort that did not $(n=8)$. No significant differences exist between the two cohorts with the exception of the addition of the LLfT course to the credential program requirements. Though the number of credential program participants doubled between 2007 and 2009, this was not due to a change in entrance requirements.

The PACT is one of three state-approved portfolio assessment models pre-service teachers must complete in order to earn state licensure. Modeled after the portfolio assessments of the National Board for Professional Teaching Standards, the INTASC (Interstate New Teacher Assessment and Support Consortium) and the Connecticut State Department of Education ("A Brief Overview of the PACT Assessment System”, n.d.), secondary science teacher candidates complete a subject-specific Teaching Event. The Teaching Event consists of one planning, instruction, assessment, and reflection cycle that is centered on key scientific concepts and scientific inquiry. Candidates submit written lesson plans for a three to five day learning segment involving "critical teaching and learning tasks in the credential area," an assessment tool, student work samples, a video of their teaching, and a written reflection ("A Brief Overview of the PACT Assessment System", n.d.). These materials are submitted and scored using a published rubric to determine competency to earn a single subject teaching credential. Participants submit the PACT Teaching Event at the beginning of the third quarter of study in the credential program. 
DEVELPOING PSTS' ABILITY TO ATTEND, ANALYZE, AND RESPOND

Because the PACT requires pre-service science teachers to plan, enact, and reflect on an instructional sequence using video, it is well aligned with the skills of interest in this study. Portions of the PACT that specifically assess these skills were isolated for analysis (see Table 1).

$$
\text { *** Insert Table } 1 \text { here *** }
$$

\subsection{Analysis}

Data analysis took place in several phases. To begin, science candidates' PACT Teaching Event responses were de-identified of any personal and field-work information. The first author then selected a random sample of PACT responses from six candidates, three from the LLfT cohort and three from the non-LLfT cohort, and used a sentence-by-sentence, open coding technique (Corbin \& Strauss, 2008) to capture candidates' noticing in their analyses of teaching and similarities and differences related to the three sub-skills: attending, analyzing, and responding. The first author then wrote analytic memos for each case informed by prior research on teacher noticing, lesson analysis, and reflection (Davis 2006; Hiebert et al., 2007; Levin, Hammer, \& Coffey, 2009; Mason, 1998; Santagata, 2011; van Es, 2011; van Es \& Sherin, 2002). The goal was to capture the focus and content of candidates' attention and analysis (e.g. student thinking, student behavior, teacher behavior, classroom climate, science content), the level of detail used to describe and analyze events, and the relationship between what they observed, their analyses, and their suggestions for improving teaching. The first author was blind to cohort membership while reviewing and writing analytic memos.

Using these memos, the authors reviewed the open codes to develop a three-level framework to characterize differences between cases for each skill. The resulting framework is displayed in Table 2. 
In this framework, attending is concerned with what candidates focus their attention on when they observe their teaching. Analyzing is concerned with their interpretation and sense-making of the events that they highlighted. Responding is concerned with how participants took up and used student ideas to inform their teaching and propose appropriate next steps in a logical way. The six cases were then recoded using the proposed framework by a graduate research team. The research team discussed variation in case ratings until consensus was reached (Creswell \& Miller, 2000). Issues raised in the discussion were used to further clarify and refine the operational definitions of the framework in an iterative fashion (Corbin \& Strauss, 2008).

In the third phase of analysis, we applied the framework to the additional cases $(n=24)$ to examine any differences that existed between cohorts in the level of sophistication for all three skills (attending, analyzing, and responding). We reviewed the candidates' responses to all three PACT questions and then assigned an overall score for each category (Miles \& Huberman, 1994). Sophistication scores were assigned a numerical value to reflect the ordinal nature of the data as follows: low $=1$, medium $=2$, and high $=3$. To ensure inter-rater reliability, members of the research team independently coded a randomly-selected subset of five cases. Inter-rater agreement of $86 \%$ was achieved across the three skills. We then conducted a Mann-Whitney U test to examine differences between LLfT and non-LLfT participants as compared to each other on each of the three skills (attending, analyzing, and responding) and their combined rank score on the three skills.

To explore the relationship between skills, we analyzed all cases without respect for cohort membership. The cohorts were combined for this analysis because it was proposed that though LLfT participants would demonstrate more sophisticated levels of attending, analyzing, and responding, there would be no theoretical difference in why skills co-occur as a result of the 
DEVELPOING PSTS' ABILITY TO ATTEND, ANALYZE, AND RESPOND

LLfT course. Because the small sample size violates the requirements for a Chi squared test, and the data are ordinal rather than simple categorical in nature, Kendall's Tau values were calculated to determine the strength of the relationship between the skills across all cases (attending x analyzing; attending $\mathrm{x}$ responding; analyzing $\mathrm{x}$ responding).

To understand the extent to which the quality of scientific inquiry in the lessons candidates chose to feature in their PACT responses may have influenced the sophistication of their analyses, we used the "Essential Features of Classroom Inquiry and Their Variations" framework from the Inquiry and the National Science Education Standards: A Guide for Teaching and Learning (NRC, 2000, p. 29) to code their lessons. The National Science Education Standards framework identifies a continuum of inquiry with highly teacher-directed inquiry at one end to highly student-directed inquiry at the other end. Each lesson plan was given a score of 1-4 on the framework, with four representing the most student-directed and one the most teacher-directed. A t test was then used to test for statistically significant differences between the cohorts.

\section{Results}

Analysis of the coding using Mann Whitney U and Kendall Tau tests revealed noteworthy differences between the LLfT and non-LLfT cohorts with respect to their sophistication in attending, analyzing, and responding to student ideas. Analysis of the relationship between the three skills of attending, analyzing, and responding across all cases (LLfT and non-LLfT) indicates it was unlikely for candidates to score at high levels of sophistication in analyzing and responding unless candidates also scored at high levels of sophistication in attending. This relationship indicates that these skill pairs (attending and analyzing, analyzing and responding) work in concert when pre-service teachers attempt to make 
DEVELPOING PSTS' ABILITY TO ATTEND, ANALYZE, AND RESPOND

sense of student ideas to inform instruction. Sophisticated attending affords but does not

guarantee sophisticated analysis; moreover, sophisticated analyses set candidates up to be able to propose logical instructional responses to student ideas. We discuss these findings below and present examples from participants PACT responses to support our analysis.

\subsection{Differences between Cohorts' Analyses of Teaching}

When comparing the two different groups, data analysis revealed that LLfT candidates were more sophisticated in attending to specific instances of student thinking, analyzing this evidence, and commenting on adjusting instruction in response to a student idea as compared to the cohort that did not enroll in the course. Table 3 displays the differences between the two cohorts in terms of level of sophistication in all three skills. We observed the largest difference between the cohorts in the sophistication of attending to student thinking about the collection, analysis, and interpretation of data from a scientific inquiry.

\section{*** Insert Table 3 here $* * *$}

Looking at the distribution of the level of sophistication for the two cohorts in Table 3, although there are low scoring individuals in both groups, most of the candidates who participated in the video based course scored in the medium to high range for the three skills, while a greater number of the candidates who did not experience the course scored in the low to medium range for all three skills. Also noteworthy is that only two non-LLfT candidates scored in the high sophistication range for any one skill, on the dimension of attending.

In terms of the framework, we observed high levels of sophistication for over $60 \%$ of candidates in the video-based course compared to only $25 \%$ of the comparison group $(\mathrm{t}(22)=1.56 ; \mathrm{p}=0.07)$. More than half of both cohorts' analysis skills were coded as medium sophistication, suggesting they were using some evidence to support the claims they made in 
DEVELPOING PSTS' ABILITY TO ATTEND, ANALYZE, AND RESPOND

their PACT responses when prompted to do so, but only members of the LLfT cohort showed high levels of analysis skill by consistently citing evidence in their responses. Finally, $75 \%$ of the course participants identified and described acting on or proposing a response to a specific student idea, compared to $50 \%$ of the comparison group $(\mathrm{t}(22)=1.58 ; \mathrm{p}=0.07)$.

The distribution of scores across the three levels of sophistication shown in Table 3 suggests that the candidates who enrolled in the video-based course demonstrated higher levels of sophistication in each skill. To explore this further, an overall mean sophistication score was calculated for both cohorts for each skill by summing each candidate's scores on each skill (low $=1$, medium $=2$, high $=3$ ) and obtaining the mean score for each cohort. Analysis reveals that the cohorts are marginally statistically significantly different in their demonstration of attending and responding on the PACT (see Table 4).

\section{*** Insert Table 4 here $* * *$}

Though the differences in sophistication for the skill of analyzing did not reach statistical significance, the difference between the two cohorts shows the same pattern as attending and responding with LLfT candidates demonstrating higher sophistication than those who did not take the course. When these small but appreciable differences in the sophistication of each skill are aggregated to generate a mean total sophistication score for both cohorts, the LLfT candidates' responses are statistically significantly more sophisticated. The following excerpts from candidate responses typical for each cohort illustrate these differences.

Roger, a non-LLfT candidate, shared a segment from a middle school general science lesson in which he asked students to work in groups to develop a test to determine the salinity level of a solution that would yield the "crispiest," or most turgid, potato slice. They were provided materials and equipment such as salt, water, a triple beam balance, beakers, and a 
DEVELPOING PSTS' ABILITY TO ATTEND, ANALYZE, AND RESPOND

graduated cylinder to develop their test and collect data. Roger defined the goal for this lesson

for students to design a controlled experiment, collect data, and identify sources of error. When

prompted to analyze how he promoted student inquiry through the collection and analysis of

data, he wrote the following:

Specifically, the inquiry lab seen in the first clip highly engaged the students as they were allowed to explore a scientific problem using methods they created themselves. They were able to have fun trying to solve a problem on their own, using their own creativity, rather than being told to follow a very structured lab procedure.

Rather than focus on the substance of students' scientific thinking, Roger mentioned the importance of students to "have fun," use their "creativity," and solve a problem "on their own." He uses general language to describe students' participation. He also uses general language in the way he frames his learning goal. Although the goal was mentioned, it was procedural rather than conceptual in nature and not specific to the content of focus. Though concepts of osmosis, diffusion, and the role of the cell wall in plant cells could have been potential topics of investigation, they were not discussed in this lesson or in the subsequent lesson.

Later in the analysis, Roger responded to a prompt to describe what he did to monitor student progress. Roger then explained that he conducted a demonstration of one method to determine the "crispiest potato" and charged his students with finding any errors he made during his procedure. He wrote:

During the demonstration, I asked the students to write down the errors that they spotted. At the end of the demonstration, I asked the students to tell me what they noticed. I then used these observations to further discuss the importance of the quality of data in an experiment. I directly questioned the students so that they would make the discovery that all of the errors made had to do with just one potato. I did this after all errors had been reported by asking different students which potato I had made the error with. Each student stated that the potato I had made the error with was potato $\mathrm{C}$. I then related this discovery back to the graph to show how great of an effect the errors had on my data. This questioning helped 
DEVELPOING PSTS' ABILITY TO ATTEND, ANALYZE, AND RESPOND

keep the students engaged and interested in the outcome of the experiment as well as obtain a greater understanding of the learning objective.

Several features stand out in this response. First, it is teacher-centered and focused almost exclusively on the teacher's own actions. Roger makes one mention of an idea generated by the students - they observed "that the potato I had made the error with was potato C." But he does not elaborate on this idea except to say that he linked this response to the bar graph he created to demonstrate the results. He closes his response with a claim that his questioning kept the students "engaged and interested," but does not provide any specific evidence to support this claim. Second, though Roger's lesson is designed to develop students' skills in data collection and he claims that he provides freedom for students to develop their own procedures, it is not in the service of a broader conceptual goal of cellular transport or a "big idea" such as the relationship of structure to function. Third, Roger's attempt to engage students in identifying his errors, in essence figuring out what he already knows in a type of guessing game, is not in the spirit of inquiry as advocated by the Next Generation Science Standards (2012). In this context, his attention to student ideas is different than attending to students' novel thinking. He is not attempting to uncover and build on student ideas, but rather to lead students to his own "correct" answer. We do not know what meaning Roger draws from his students' answer to know if or how well students understood why the procedures used on potato $C$ changed the results.

In contrast, Walter's PACT response is typical of the LLfT candidates. His Biology students were collecting data to understand the factors that influence ATP production and the role of oxygen and carbon dioxide in cellular respiration. Walter's students prepared a sample of water and Bromothymol Blue and blew bubbles of carbon dioxide into it for a set amount of time under different conditions (when at rest, after light exercise, and after vigorous exercise). The more acidic the water became from the introduction of the carbon dioxide, the more sodium 
DEVELPOING PSTS' ABILITY TO ATTEND, ANALYZE, AND RESPOND

hydroxide would be required to return it to its original color. A noteworthy aspect of his response is that he highlights two examples of how he helped students deepen their knowledge of the science concept while collecting data. In the first, he describes an interaction with one of the lab groups that is confused as to why their solution requires so much more sodium hydroxide than their classmates' solutions.

The students discussed how it was because the person performing the experiment was a tuba player. The dialogue about the tuba player got the students building on their prior knowledge that all individuals are different and that by being a tuba player you would probably have a greater lung capacity. I then asked the group that if the solution is taking a long time to turn colors is the solution very acidic or basic and the students answered acidic, which I responded by asking, meaning it has a lot of and they answered $\mathrm{CO}_{2}$. Therefore, I am scaffolding the students into understanding the concepts and recognizing the connections of how one piece of information tells us some part of the reaction that is occurring.

Walter's response is different than Roger's in several ways. First, he uses specific, student-centered examples to support his claim that he is helping "further the students' knowledge and skills while collecting data." He provided a detailed example of students attempting to make sense of their lab experience. They expressed confusion as to why their results were taking so long and suggested it might be because one of them was a tuba player and therefore had greater lung capacity. Walter pursued this idea, pushing the students to make the connection between what might be important about lung capacity in relation to the amount of carbon dioxide he introduced into the solution, how that changed the $\mathrm{pH}$ of the solution, and why that $\mathrm{pH}$ change required more sodium hydroxide to neutralize it.

Not only is Walter specific in his description of the student thinking in this interaction, he is also specific about the science concept he identifies for students - the relationship between carbon dioxide, blood $\mathrm{pH}$, and aerobic capacity. It was not enough that students recognize the relationship but that they understood the biological mechanism that drives the relationship 
DEVELPOING PSTS' ABILITY TO ATTEND, ANALYZE, AND RESPOND

between the three variables. This level of attention in the description and content of student thinking is emblematic of a typical LLfT candidate response.

Another distinction in Walter's PACT response is how he built on students' science thinking during instruction. For example, he wrote about how he pressed the class during their examination of their pooled data displayed on the board. He questioned students about why different groups' data may be different from each other. The students responded that "individuals are different." As in the previous example, he elaborated on his follow-up response to his students' answer to document how he monitored student progress toward the learning goal:

I then furthered the students thinking by asking, "what would be different about people?" The students then came up with responses about different people take in different levels of oxygen, some people are more fit, and different muscle mass. When students would suggest these differences, I would ask the students to expand on their thinking and why it would make a difference. Therefore, the students were building on their knowledge by connecting the content from lecture to the concepts involved in the lab.

As before, Walter makes a claim about what he is attempting to do, in this case drawing students' attention to the connection between physiological differences and the resulting changes in cellular respiration rate, provides a detailed account of what his students say and how he responds to their ideas, and then makes a statement about the significance of the evidence he presented. Additionally, Walter is calling out specific interactions that involve the students' making meaning of a specific science concept, not just the skill of collecting data. The details he includes in his narrative serve as evidence to support a claim he is making about what students learned and how he assisted them in the process. Linking student ideas and instructional actions was more common in the LLfT candidates' responses than the non-LLfT candidates' responses.

Responses like Walter's that promoted conceptual understanding in addition to skill development in data collection raised a question about the different affordances lesson quality 
DEVELPOING PSTS' ABILITY TO ATTEND, ANALYZE, AND RESPOND

had on participants' ability to demonstrate sophistication in attending, analyzing, and responding. A t test between the inquiry scores for the LLfT and non-LLfT candidates' lesson plans revealed that there was little to no variation between cohorts in the level of inquiry of the featured lessons. Whether participants chose to highlight and unpack student thinking or not, or highlight student thinking about concepts versus skills was not related to the level of inquiry in task featured in their PACT lesson.

The results shown in Tables 3 and 4 and the examples that followed suggest that preservice teachers can develop skills for analyzing teaching, but the nature of the relationship between these skills, namely, attending, analyzing and responding, remained unexplored. Through researchers have examined discrete skills such as attending, analyzing, and responding to student ideas (Franke \& Kazemi, 2001; Levin, Hammer, \& Coffey, 2009; Santagata, Zannoni, \& Stigler, 2007; Star \& Strickland, 2008; van Es \& Sherin, 2002, 2008), there is consensus that these skills are leveraged in concert by teachers to make sense of classroom interactions and student learning (Davis, 2006; Dewey, 1933; Mason, 2011; Schön, 1983; Zeichner \& Liston, 1996). Further investigation into how the three skills co-relate could enhance our understanding of how pre-service teachers develop their reflective capacities. In particular, we seek to understand if sophistication in one skill is a prerequisite for another skill or if all three skills can be developed simultaneously. We now turn to examine the relationships between the three skills of attending, analyzing and responding.

\subsection{Relationship Between Attending, Analyzing, and Responding}

To answer the second research question, we explored the relationships between the three skills identified by examining if the presence or absence of any one skill related to the presence or absence of any other skill. In particular, we hypothesized that evidence of sophisticated 
DEVELPOING PSTS' ABILITY TO ATTEND, ANALYZE, AND RESPOND

analysis and adjustments of teaching with respect to student ideas would be absent without documentation of attention to and analysis of those ideas in written reflections.

A comparison of the three skills between the LLfT and non-LLfT cohorts in Table 5 reveals patterns in their co-occurrences with respect to level of sophistication.

\section{*** Insert Table 5 here $* * *$}

Over $60 \%$ of LLfT participants demonstrated medium or high levels of sophistication in all three skills, compared to $25 \%$ of the comparison group. Further, none of the participants in the comparison group demonstrated high levels of sophistication in all three areas and a quarter of this group exhibited low levels of sophistication in multiple skills. In contrast, the majority of candidates from the video-based course scored at medium and high levels of sophistication in all three skills; whereas, the majority of comparison group scored at medium and high levels of sophistication in only two skills combined.

These results led us to question how sophistication in one skill may be related to sophistication on other skills. To examine these relationships, we explored each pair of skills (attending $\mathrm{x}$ analyzing, analyzing $\mathrm{x}$ responding, and attending $\mathrm{x}$ responding) in turn. Table 6 displays a relationship between sophistication in all three skill pairs.

*** Insert Table 6 here ***

We anticipated that there would be statistically significant relationships between the levels of sophistication between all skill pairs, that low levels of sophistication in some skills would inhibit candidates from demonstrating high levels of sophistication in others, and that candidates would be more likely to demonstrate high levels of sophistication in the skill of attending compared to analyzing and responding. 
DEVELPOING PSTS' ABILITY TO ATTEND, ANALYZE, AND RESPOND

The first skill pair we analyzed was attending and analyzing. As expected, candidates who demonstrated low sophistication in attending were unlikely to demonstrate high levels of sophistication in analyzing and vice versa. The Kendall's tau B coefficient indicates a positive and highly statistically significant relationship between these two skills, similar to the relationship found in prior research (Santagata, 2011; van Es, 2011). This pairing of attention to student ideas and analysis of what those ideas tell the teacher about student understanding is an indication that the teacher is exhibiting more selective attention and focusing on significant classroom events rather than attending to a wide range of events that take place in the classroom (van Es \& Sherin, 2002).

An example of this is in Walter's response detailed above. He called out specific student ideas about how the amount of carbon dioxide is influenced by differences between people. Rather than accepting "people are different" as an acceptable answer to explain the variation in carbon dioxide production and moving on, he probed students to uncover what his students meant when they said that people were "different." Walter is not just simply seeking "correct" answers; rather he is seeking to more fully understand his students' ideas and the depth of their understanding by asking them to elaborate on their answers. Walter then interpreted what these elaborations tell him about his students' developing understanding about the relationship between cellular respiration rate and physiology.

We now turn to the relationship between analyzing student thinking and responding to student ideas. The Kendall's tau value supports the qualitative analysis that these skills appear to be tightly coupled. A positive and highly statistically significant pattern was observed between analyzing and responding. High sophistication in analyzing tended to co-occur with high sophistication in responding, medium sophistication in analyzing with medium sophistication of 
DEVELPOING PSTS' ABILITY TO ATTEND, ANALYZE, AND RESPOND

responding, and low sophistication in analyzing with low sophistication in responding.

Participants were slightly more likely to demonstrate sophistication in analysis than in responding to student ideas. Additionally, there was only one case of highly sophisticated analysis of student ideas without a highly sophisticated response and no cases of highly sophisticated responses with only medium or low levels of sophistication in analyzing.

To score at high levels of sophistication in responding required participants to propose logical changes to future lessons and to adjust instruction in real-time to a student idea. A medium level of sophistication required that participants propose logical changes to future lessons. To be considered logical, the responses had to be informed by evidence they cited in their PACT narrative. An example of the typical logic for proposed adjustments is Walter's response to the analysis of his lesson. He identified a learning goal for his biology students: that they should understand the relationship between exercise, oxygen demand, pulse, and ATP production. This example of homeostasis is an important concept in high school biology. Yet, when prompted to suggest a possible change he would make to this lesson in the future, he mentioned that many students did not write extensive responses to the prompts on their written lab report. He proposed the following: "A change I would make would be to place lines on the lab report pages, which would give the students an idea of how much writing would be required for each question." This proposed adjustment, while related to how students may experience writing a lab report, has little relevance to his stated learning goal, and therefore, scored as a less sophisticated response for responding. Though it is accompanied by a justification based on what he noticed about his students' writing, it is not a response to students' ideas about homeostasis. These types of management and behavioral adjustments were common among all participants. They serve as an important reminder of how difficult it can be for pre-service teachers to act 
DEVELPOING PSTS' ABILITY TO ATTEND, ANALYZE, AND RESPOND

upon their analysis of student ideas in the moment by adjusting instruction. In fact, only three of twenty-four participants scored at high levels of responding.

The final skill pair to be analyzed was between attending and responding. Participants were more likely to demonstrate higher levels of sophistication in attending than responding. Moreover, participants who demonstrated low sophistication in attending were unlikely to demonstrate high levels of sophistication in responding. However, the qualitative examples combined with the low and non-statistically significant Kendall Tau coefficient for this skill pair suggests that these two skills are not meaningfully related to each other. That is to say, it is reasonable to conclude that highly sophisticated analysis depends on highly sophisticated attention to student ideas. In turn, highly sophisticated responses depend on highly sophisticated analyses of student ideas. Though teachers frequently react to students in the act of teaching, the quality of these reactions may be lacking in quality (Scribner, 2003). Thus, attention without analysis does not often yield sophisticated responses to student thinking.

Finally, an examination of the numbers of candidates who demonstrated medium and high levels of sophistication on the three skills indicates that these skills do not appear to develop at the same rate. Mid to high levels of sophistication in analyzing were more common than mid to high levels of sophistication in responding. Mid to high levels of sophistication in attending were more common than mid to high levels of sophistication in analyzing. This suggests that analyzing and responding are more difficult for pre-service teachers than attending. A t test confirms this finding $(\mathrm{t}(43)=2.13 ; \mathrm{p}=.04)$. Implications of these results follow.

\section{Discussion}

The findings of this study reveal that the candidates who participated in the video-based course, Learning to Learn from Teaching, demonstrated more sophistication in all three 
DEVELPOING PSTS' ABILITY TO ATTEND, ANALYZE, AND RESPOND

dimensions as compared to those who did not take the course. This suggests that a video-based course can help teachers learn to conduct sophisticated analyses of their own teaching. Though research on reflection (Dewey, 1933; Schön, 1983), awareness (Mason, 1998), and noticing (Sherin \& van Es, 2009) make it clear that these are recursive processes, these results suggest that skilled examinations of learning and teaching rely on skilled "noticing" (van Es \& Sherin, 2002). Though nearly half of the candidates from both cohorts tended to score either at the low level in every skill or at the high level in every skill, the rest of the candidates demonstrated what has been described as "mixed" noticing (van Es, 2011; van Es \& Sherin, 2002). The low occurrence of sophisticated analysis and responding without sophisticated attention suggests that time spent teaching pre-service teachers how to attend to student ideas may be a critical prerequisite skill for more integrated, disciplined, and effective reflection proposed by research (Hiebert et al., 2007; Rodgers, 2002b).

Fortunately, the difference in the distribution of medium to high levels of sophisticated attention between the two cohorts indicates that selective attention to student thinking can improve with instruction. Despite three months' time separating completion of the video-based course and completion of the PACT assessment, course participants demonstrated sophisticated attention to student ideas in their written analyses of their own teaching. This is significant because "exposure to a learning opportunity does not guarantee learning nor does it necessarily result in changes in classroom practice" (Lustik \& Sykes, 2006, p. 2). Also striking is the near absence of documentation of attention to student thinking by the comparison group despite the explicit prompting of the PACT assessment to do so.

The results of this study suggest three important conclusions. First, consistent with prior research, the results of this study show that pre-service teachers can learn to attend to student 
DEVELPOING PSTS' ABILITY TO ATTEND, ANALYZE, AND RESPOND

ideas when instructed to do so (Davis, 2006; Levin, Hammer \& Coffey, 2009; Smithey, 2009;

Star et al., 2011). The participants in the LLfT course focused their attention and analysis on student thinking as opposed to other superficial or less note-worthy details of the science classroom. This disciplined awareness, or noticing, is more typical of expert practitioners (Berliner, 2001; Mason, 2002), and persisted beyond the conclusion of the course. Because prior research indicates that pre-service teachers may tend to ignore, discount, discard, or forget what was learned during their preparation programs, their continued use of these skills is encouraging.

Second, while pre-service teachers were able to attend to student ideas, they tended to experience difficulty using those ideas as evidence to analyze teaching and learning and using the results of analysis to respond to those ideas. The results above reveal that pre-service teachers can attend to what students say and become accustomed to documenting it in written reflections. The number of participants scoring at high levels of sophistication was greatest in the skill of attending, then analyzing, with responding having the lowest number of participants scoring at high levels of sophistication. The distribution of participants' scores across the three dimensions of low, medium, and high sophistication of the three skills indicate that attending, analyzing, and responding to student ideas appear to be successively difficult skills. Knowing what is relevant and what is not about a situation and connecting these small events to broader themes of learning and pedagogy appears to be particularly difficult for pre-service teachers to document (Davis, 2006; Levin, Hammer, \& Coffey, 2009).

One possible explanation for the difficulty linking attending and responding could be that analysis is the bridging skill between attending and responding. Analysis is what gives reason to the other two skills and distinguishes them as part of effective reflection rather than simply seeing and reacting. Such analysis is challenging even for experienced teachers. Further 
DEVELPOING PSTS' ABILITY TO ATTEND, ANALYZE, AND RESPOND

complicating the relationship between skills is how reflection and analysis are framed for teachers. Levin and colleagues found that the focus on covering the curriculum and establishing routines in field sites may influence whether or not novice teachers attend to student thinking and how teachers respond to student ideas (Levin, Hammer, \& Coffey, 2009). They suggest that developing teacher candidates' framing of instructional interactions is essential for helping them shift to adopt a more student-centered, responsive approach to instruction.

Though participation in the video-based course did impact the development of individual skills of attending, analyzing, and responding to student ideas, substantial numbers of these course participants did not demonstrate medium or high levels of sophistication in all three skills in tandem. It is important to consider that the course only lasted ten weeks and the reflective skills that were the center of the course were not explicitly reinforced in any other courses in the program. The influence that participation in the course appears to have had on pre-service teachers' ability to systematically analyze teaching and learning despite the limited scope of the intervention is highly encouraging. It may be the case that more tightly coupling opportunities to learn to systematically analyze teaching with traditional methods courses in which students learn pedagogical strategies grounded in the discipline can help candidate make progress on learning to respond to student ideas in the moment based on analyses of student thinking and learning in a lesson. Examining the impact of embedding structured opportunities to build this professional analytic skill set throughout a credential program is an important subject for future inquiry.

\section{Conclusion}

The objective of teacher education programs is to prepare future professionals to develop the knowledge, capacities and dispositions to learn in and from their practice over time (FeimanNemser, 2001). "Professionalism starts from the proposition that thoughtful and ethical use of 
DEVELPOING PSTS' ABILITY TO ATTEND, ANALYZE, AND RESPOND

knowledge must inform practice" (Darling-Hammond, 2005, p.4). The knowledge that informs practice is student voices. Future teaching professionals must learn what to attend to, how to direct attention to important interactions, how to interpret what they see and hear, and how to best to respond if they are to be effective, ethical professionals (Ball \& Cohen, 1999). Teacher preparation programs must continue to develop these capacities while researchers track the development of these skills beyond teacher education programs and into the induction years of teaching. Such research will provide important insights into how these capacities develop in relation to each other over time and the influence they have on teachers learning in and from their practice. Longitudinal studies following pre-service teachers into the early years of practice will also yield valuable information about the influence courses like Learning to Learn from Teaching have on teachers' professional trajectories. 


\section{References}

A brief overview of the PACT assessment system, (n.d.). Retrieved from www.pacttpa.org.

American Association for the Advancement of Science. (2009). Benchmarks for scientific literacy. New York: Oxford University Press.

Ball, D. L. \& Cohen, D. K. (1999). Developing practice, developing practioners: Toward a practice-based theory of professional education. In L. Darling-Hammond and G. Sykes (Eds.), Teaching as the learning profession: Handbook of policy and practice (pp. 3-32). San Francisco: Jossey-Bass.

Borko, H., \& Livingston, C. (1989). Cognition and improvisation: Differences in mathematics instruction by expert and novice teachers. American Educational Research Journal, 26(4), 473-498.

Berliner, D. C. (2001). Learning about and learning from expert teachers. International Journal of Educational Research, 35(5),463-482.

Blythe, T. (1997). The teaching for understanding guide. San Francisco, CA: Jossey Bass.

Carter, K., Cushing, K., Sabers, D., Stein, P., \& Berliner, D. (1988). Expert-novice differences in perceiving and processing visual classroom information. Journal of Teacher Education, 39(3), 25-31.

Copeland, W. D., Birmingham, C., DeMeulle, L., D'Emidio-Caston, M., \& Natal, D. (1994). Making meaning in classrooms: An investigation of cognitive processes in aspiring teachers, experienced teachers, and their peers. American Educational Research Journal, 31(1), 166-196.

Corbin, J. \& Strauss, A. (2008). Basics of aualitative research: Third edition. Thousand Oaks, CA: Sage Publications.

Creswell, J. \& Miller, D. (2000). Determining validity in qualitative inquiry. Theory into Practice, 39(3), 124-130.

Darling-Hammond, L. (2010). Recognizing and developing effective teaching: What policy makers should know and do. Partnership for Teacher Quality Policy Brief, May, 2010. Retrieved from http://www.nea.org/assets/docs/HE/Effective_Teaching__Linda_Darling-Hammond.pdf.

Darling-Hammond, L. (2005). Developing professional development schools: Early lessons, challenge, and promise. In L. Darling-Hammond (Ed.), Professional development schools: Schools for developing a profession (pp. 1-27). New York: Teachers College Press. 
DEVELPOING PSTS' ABILITY TO ATTEND, ANALYZE, AND RESPOND

Darling-Hammond, L. \& Bransford, J. (2005). Preparing teachers for a changing world: What teachers should know and be able to do. San Francisco: Jossey-Bass.

Davis, E. (2006). Characterizing productive reflection among preservice elementary teachers: seeing what matters. Teaching and Teacher Education, 22(3), 281-301.

Davis, E., Petish, D, \& Smithey, J. (2006). Challenges new science teachers face. Review of Educational Research, 76(4), 607-651.

Dewey, J. (1933). How we think. Buffalo, NY: Prometheus Books.

Erickson, F. (2011). On noticing teacher noticing. In M. Sherin, V. Jacobs, \& R. Philipp (Eds.), Mathematics teacher noticing: Seeing through teachers' eyes, (Chapter 2). [Kindle version.]

Ermeling, B. A. (2010). Tracing the effects of teacher inquiry on classroom practice. Teaching and Teacher Education, 26(3), 377-388.

Feiman-Nemser, S. (2001). From preparation to practice: Designing a continuum to strengthen and sustain teaching. The Teachers College Record, 103(6), 1013-1055.

Franke, M. \& Kazemi, E. (2001). Learning to teach mathematics: Focus on student thinking. Theory into Practice, 40(2), 102-109.

Goldhaber, D., \& Anthony, E. (March 8, 2004). Can teacher quality be effectively assessed? The Urban Institute. Retrieved from http://www.urban.org/UpLoadedPDF/410958_NBPTSOutcomes.pdf.

Gleick, J. (2011). The information: A history, a theory, a flood. Harper Collins. [Kindle version.]

Hammer, D. (2000). Student resources for learning introductory physics. American Journal of Physics, Physics Education Research Supplement, 68(S1), S52-S59.

Hammerness, K., Darling-Hammond, L., \& Bransford, J. (2005). How teachers learn and develop. In L. Darling-Hammond and J. Bransford (Eds.), Preparing teachers for a changing world: What teachers should know and be able to do. San Francisco: JosseyBass.

Hiebert, J., Morris, A., Berk, D., \& Jansen, A. (2007). Preparing teachers to learn from teaching. Journal of Teacher Education, 58(1), 47-61.

Hufferd-Ackles, K., Fuson, K.C., \& Sherin, M.G. (2004). Describing levels and components of a math-talk learning community. Journal for Research in Mathematics Education, 35(2), 81-116.

Jacobs, V. R., Lamb, L. L., \& Philipp, R. A. (2010). Professional noticing of children's mathematical thinking. Journal for Research in Mathematics Education, 41(2), 169-202. 
Little, J.W. \& Horn, I.S. (2007). 'Normalizing' problems of practice: Converting routine conversation into a resource for learning in professional communities. In L. Stoll and K.S. Louis (Eds.) Professional Learning Communities: Divergence, Detail and Difficulties (pp. 79-92). Maidenhead, UK: Open University Press.

Lemke, J. (2002). Discursive technologies and the social organization of meaning. Folia Linguistica, 35(1-2), 79-96.

Levin, D. M., Hammer, D., \& Coffey, J. E. (2009). Novice teachers' attention to student thinking. Journal of Teacher Education, 60(2), 142-154.

Loughran, J. (2002). Effective reflective practice: In search of meaning in learning about teaching. Journal of Teacher Education, 53(1), 33-43.

Lloyd, M. M., \& Mukherjee, M. (2012, October). Tell me what you see: Pre-service teachers' recognition of exemplary digital pedagogy. Paper presented at Australian Computers in Education Conference, Perth, Australia.

Mason, J. (1998). Enabling teachers to be real teachers: Necessary levels of awareness and structure of attention. Journal of Mathematics Teacher Education, 1, 243-267.

Mason J. (2002). Researching your own practice: The discipline of noticing. London: Routledge Falmer.

Mason, John (2011). Noticing: roots and branches. In M. Sherin, V. Jacobs, and R. Philipp (Eds.), Mathematics Teacher Noticing: Seeing Through Teachers' Eyes, (Chapter 3). [Kindle version.]

Miles, M. B. \& Huberman, A. M. (1994). Qualitative Data Analysis: Second Edition. Thousand Oaks, CA: Sage Publications.

Ministry of Education-Singapore (2013). Science Syllabus: Primary. Retrieved from www.moe.gov.sg/education/syllabuses/sciences/files/science-primary-2014.pdf.

Morris, A. K. (2006). Assessing pre-service teachers' skills for analyzing teaching. Journal of Mathematics Teacher Education, 9(5), 471-505.

National Research Council. (2000). Inquiry and the National Science Education Standards: A Guide for Teaching and Learning. Committee on Development of an Addendum to the National Science Education Standards on Scientific Inquiry, Center for Science, Mathematics, and Engineering Education. The National Academies Press. Retrieved from http://www.nap.edu/download.php?record_id=9596.

National Research Council. (2007). Taking Science to School: Learning and Teaching Science in Grades K-8. Committee on Science Learning, Kindergarten Through Eighth Grade. 
Richard A. Duschl, Heidi A. Schweingruber, and Andrew W. Shouse, (Eds.). Board on Science Education, Center for Education, Division of Behavioral and Social Sciences and Education. The National Academies Press. Retrieved from http://www.nap.edu/download.php?record_id=11625.

National Research Council. (2012). A Framework for K-12 Science Education: Practices, Crosscutting Concepts, and Core Ideas. Committee on a Conceptual Framework for New K-12 Science Education Standards. Board on Science Education, Division of Behavioral and Social Sciences and Education. National Academies Press. Retrieved from http://www.nap.edu/download.php?record_id=13165.

Nicol, C., \& Crespo, S. (2004). Learning to see in mathematics classrooms. In Proceedings of the 28th Conference of the International (Vol. 3, pp. 417-424). Retrieved from ftp://134.76.12.4/pub/EMIS/proceedings/PME28/RR/RR263_Nicol.pdf.

OECD (2013). PISA 2012 Results: What students know and can do - Student performance in mathematics, reading, and science (Vol 1). Retrieved from http://dx.doi.org/10.1787/9789264201118-en.

Pang, J. (2011). Case-based pedagogy for prospective teachers to learn how to teach elementary mathematics in Korea. ZDM, 43(6-7), 777-789.

Richardson, V. (September, 1998). How teachers change. Focus on Basics, 2(C). Retrieved from http://www.ncsall.net.

Rodgers, C. (2002a). Defining reflection: Another look at John Dewey and reflective thinking. Teachers College Record, 104(4), 842-866.

Rodgers, C. (2002b). Seeing student learning: Teacher change and the role of reflection. Harvard Educational Review, 72(2), 230-253.

Rodgers, C. (2006). Attending to student voices: The impact of descriptive feedback on learning and teaching. Curriculum Inquiry, 36(2), 209-237.

Ruiz-Primo, M. A., \& Furtak, E. M. (2007). Exploring teachers' informal formative assessment practices and students' understanding in the context of scientific inquiry. Journal of Research in Science Teaching, 44(1), 57-84.

Sandoval, W. A., Deneroff, V., \& Franke, M. L. (2002, April). Teaching, as learning, as inquiry: moving beyond activity in the analysis of teaching practice. Paper presented at the annual meeting of the American Educational Research Association, New Orleans, LA.

Santagata, R. (2011). From teacher noticing to a framework for analyzing and improving classroom lessons. In M. Sherin, V. Jacobs, and R. Philipp (Eds.), Mathematics Teacher Noticing: Seeing Through Teachers' Eyes, (Chapter 10). [Kindle version.] 
Santagata, R., \& Angelici, G. (2010). Studying the impact of the lesson analysis framework on preservice teachers' abilities to reflect on videos of classroom teaching. Journal of Teacher Education, 61(4), 339-349.

Santagata, R. \& van Es, E. (2010). Disciplined analysis of mathematics teaching as a routine of practice. In J. Luebeck \& J. W. Lott (Eds.), Mathematics teaching: Putting research into practice at all levels (pp. 109-123). VII monograph of the Association of Mathematics Teacher Educators.

Santagata, R., \& Yeh, C. (2013). Learning to teach mathematics and to analyze teaching effectiveness: evidence from a video-and practice-based approach. Journal of Mathematics Teacher Education, December, 1-24.

Santagata, R., Zanoni, C., \& Stigler, J.W. (2007). The role of lesson analysis in preservice teacher education: An empirical investigation of teacher learning from a virtual videobased field experience. Journal of Mathematics Teacher Education, 10(2), 123-140.

Schoenfeld, A. H. (2011). Toward professional development for teachers grounded in a theory of decision making. ZDM, 43(4), 457-469.

Schön, D. A. (1983). The Reflective Practioner. USA: Basic Books.

Scribner J.P., (2003, April). Do-it-yourselfers or engineers? Bricolage as a metaphor for teacher work and learning. Paper presented at the annual meeting of the American Educational Research Association, Chicago, IL.

Sherin, M.G. \& van Es, E.A. (2009). Effects of video club participation on teachers' professional vision. Journal of Teacher Education, 60, 20-37.

Spitzer, S. M., Phelps, C. M., Beyers, J. E., Johnson, D. Y., \& Sieminski, E. M. (2011). Developing prospective elementary teachers' abilities to identify evidence of student mathematical achievement. Journal of Mathematics Teacher Education, 14(1), 67-87.

Star, J., Lynch, K., \& Perova, N. (2011). Using video to improve preservice mathematics teachers' abilities to attend to classroom features. In M. Sherin, V. Jacobs, \& R. Philipp (Eds.), Mathematics Teacher Noticing: Seeing Through Teachers' Eyes, (Chapter 8). [Kindle version.]

Star, J. \& Strickland, S. (2008). Learning to observe: Using video to improve preservice mathematics teachers' ability to notice. Journal of Math Teacher Education, 11(2), 107125.

Stockero, S. (2008). Using a video-based curriculum to develop a reflective stance in prospective mathematics teachers. Journal of Mathematics Teacher Education, 11(5), 373-394.

Strauss, R. P., \& Sawyer, E. A. (1986). Some new evidence on teacher and student competencies. Economics of Education Review, 5(1), 41-48. 
Stürmer, K., Könings, K. D., \& Seidel, T. (2012). Declarative knowledge and professional vision in teacher education: effect of courses in teaching and learning. British Journal of Educational Psychology, 83, 467-483.

So, Winnie Wing-Mui. (2012). Quality of learning outcomes in an online video-based learning community: potential and challenges for student teachers. Asia-Pacific Journal of Teacher Education, 40(2), 143-158.

van Es, E. (2011). A framework for learning to notice student thinking. In M. Sherin, V. Jacobs, \& R. Philipp (Eds.), Mathematics Teacher Noticing: Seeing Through Teachers' Eyes, (Chapter 9). [Kindle version.]

van Es, E. \& Sherin, M. (2008). Mathematics teachers' "learning to notice" in the context of a video club. Teaching and Teacher Education: An International Journal of Research and Studies, 24(2), 244-276.

van Es, E. \& Sherin, M. (2002). Learning to notice: Scaffolding new teachers' interpretations of classroom interactions. Journal of Technology and Teacher Education, 10(4), 571-596.

van Manen, M. (1977). Linking ways of knowing with ways of being practical. Curriculum inquiry, 6(3), 205-228.

van Zee, E., \& Minstrell, J. (1997). Using questioning to guide student thinking. Journal of the Learning Sciences, 6(2), 227-269.

Waddington, D., Nentwig, P., \& Schanze, S. (2007). Standards in science education: Making it comparable. Munster, Germany: Waxman Publishing.

Whitehurst, G. (2002). Scientifically-based research on teacher quality: Research on teacher preparation and professional development. Proceedings of the White House conference on preparing tomorrow's teachers. Retrieved from http://tepserver.ucsd.edu.

Windschitl, M., Thompson, J., \& Braaten, M. (2008). Beyond the scientific method: Modelbased inquiry as a new paradigm of preference for school science investigations. Science Education, 92(5), 941-967.

Windschitl, M., Thompson, J. \& Braaten, M. (2011). Ambitious pedagogy by novice teachers: Who benefits from tool-supported collaborative inquiry into practice and why? Teachers College Record, 113(7), 1311-1360.

Zeichner, K., \& Liston, D. (1987). Teaching student teachers to reflect. Harvard educational review, 57(1), 23-49.

Zeichner, K. \& Liston, D. (1996). Reflective teaching: An introduction. Mahwah, NJ: Lawrence Erlbaum Associates. 
Running Head: LEARNING TO ATTEND, ANALYZE, AND RESPOND

Table 1

PACT Task 3 Prompts Selected for Study Analysis

Task 3 Instructing Students and Supporting Learning

Question 3:

In the instruction seen in the clips, how did you further the students' knowledge and skills and engage them intellectually while collecting, analyzing, and interpreting data from a scientific inquiry? Provide examples of both general strategies to address the needs of all of your students and strategies to address specific individual needs.

Question 5:

Describe the strategies you used to monitor student learning during the learning task shown on the video clips. Cite one or two examples of what students said and/or did in the video clips or in assessments related to the lesson(s) that indicated their progress toward accomplishing the lessons' learning objectives.

Question 6:

Reflect on the learning that resulted from the experiences featured in the video clips. Explain how, in your subsequent planning and teaching, successes were built upon and missed opportunities were addressed. 
DEVELPOING PSTS' ABILITY TO ATTEND, ANALYZE, AND RESPOND

Table 2

Levels of Sophistication for Noticing Skills

\begin{tabular}{|c|c|c|c|}
\hline Skill & Low sophistication & Medium sophistication & High sophistication \\
\hline Attending & $\begin{array}{l}\text { Highlights classroom } \\
\text { events, teacher } \\
\text { pedagogy, student } \\
\text { behavior, and/or } \\
\text { classroom climate. No } \\
\text { attention to student } \\
\text { thinking. }\end{array}$ & $\begin{array}{l}\text { Highlights student } \\
\text { thinking with respect to } \\
\text { the collection of data } \\
\text { from a scientific inquiry } \\
\text { (science procedural } \\
\text { focus). }\end{array}$ & $\begin{array}{l}\text { Highlights student } \\
\text { thinking with respect to } \\
\text { the collection, analysis, } \\
\text { and interpretation of } \\
\text { data from a scientific } \\
\text { inquiry (science } \\
\text { conceptual focus) }\end{array}$ \\
\hline Analyzing & $\begin{array}{l}\text { Little or no sense- } \\
\text { making of highlighted } \\
\text { events; mostly } \\
\text { descriptions. No } \\
\text { elaboration or analysis } \\
\text { of interactions and } \\
\text { classroom events; little } \\
\text { or no use of evidence to } \\
\text { support claims. }\end{array}$ & $\begin{array}{l}\text { Begins to make sense of } \\
\text { highlighted events. } \\
\text { Some use of evidence } \\
\text { to support claims. }\end{array}$ & $\begin{array}{l}\text { Consistently makes } \\
\text { sense of highlighted } \\
\text { events. Consistent use } \\
\text { of evidence to support } \\
\text { claims. }\end{array}$ \\
\hline Responding & $\begin{array}{l}\text { Does not identify or } \\
\text { describe acting on } \\
\text { specific student ideas as } \\
\text { topics of discussion; } \\
\text { offers disconnected or } \\
\text { vague ideas of what to } \\
\text { do differently next time. }\end{array}$ & $\begin{array}{l}\text { Identifies and describes } \\
\text { acting on a specific } \\
\text { student idea during the } \\
\text { lesson; offers ideas } \\
\text { about what to do } \\
\text { differently next time. }\end{array}$ & $\begin{array}{l}\text { Identifies and describes } \\
\text { acting on a specific } \\
\text { student idea during the } \\
\text { lesson and offers } \\
\text { specific ideas of what } \\
\text { to do differently next } \\
\text { time in response to } \\
\text { evidence; makes logical } \\
\text { connections between } \\
\text { teaching and learning. }\end{array}$ \\
\hline
\end{tabular}


DEVELPOING PSTS' ABILITY TO ATTEND, ANALYZE, AND RESPOND

Table 3

Comparison of the Sophistication of Attending, Analyzing, and Responding to Teaching Between Two Cohorts

\begin{tabular}{lll}
\hline Skill & Non-LLfT Participants & LLfT Participants \\
\hline Attending & & \\
$\quad$ Low sophistication & $25 \%(2)$ & $13 \%(2)$ \\
Medium sophistication & $50 \%(4)$ & $25 \%(4)$ \\
$\quad$ High sophistication & $25 \%(2)$ & $63 \%(10)$ \\
Analyzing & & \\
$\quad$ Low sophistication & $25 \%(2)$ & $19 \%(3)$ \\
$\quad$ Medium sophistication & $75 \%(6)$ & $63 \%(10)$ \\
$\quad$ High sophistication & $0 \%(0)$ & $19 \%(3)$ \\
Responding & & $25 \%(4)$ \\
$\quad$ Low sophistication & $50 \%(4)$ & $56 \%(9)$ \\
$\quad$ Medium sophistication & $50 \%(4)$ & $19 \%(3)$ \\
$\quad$ High sophistication & $0 \%(0)$ & 16 \\
\hline $\mathrm{N}$ & 8 &
\end{tabular}

Note. $\mathrm{N}$ values are in parenthesis. 
DEVELPOING PSTS' ABILITY TO ATTEND, ANALYZE, AND RESPOND

Table 4

Comparison of Mean Attending, Analyzing, Responding, and Total Scores Between Two Cohorts.

\begin{tabular}{lll}
\hline Skill & Non-LLfT Candidates & LLfT Candidates \\
\hline Attending $\dagger$ & 2 & 2.5 \\
Analyzing & 1.75 & 2 \\
Responding $\dagger$ & 1.5 & 1.9 \\
Total Score $*$ & $5.3(4-7)$ & $6.4(3-9)$ \\
$\mathrm{N}$ & 8 & 16 \\
\hline Note. Mann-Whitney results for attending $\mathrm{U}(23)=88.0, \mathrm{Z}=1.47, .07$. For analyzing $\mathrm{U}(23)=$ \\
$77.0, \mathrm{Z}=0.80, .21$. For responding $\mathrm{U}(23)=86, \mathrm{Z}=1.35, .10$. For total score $\mathrm{U}(23)=95.0, \mathrm{Z}=$ \\
$\begin{array}{l}1.90, .03 . \text { All tests were one-tailed. Range is in parentheses. } \\
* \mathrm{p}<.05 . \dagger \mathrm{p} \leq .10\end{array}$
\end{tabular}


DEVELPOING PSTS' ABILITY TO ATTEND, ANALYZE, AND RESPOND

Table 5

Comparison of LLfT and Non-LLfT Participants' Sophistication of PACT Responses in Combination

\begin{tabular}{lll}
\hline Skill & Non-LLfT cohort & LLfT cohort \\
\hline Low sophistication in all areas & 0 & $6 \%(1)$ \\
Medium or high sophistication in one area only & $25 \%(2)$ & $6 \%(1)$ \\
Medium or high sophistication in two areas only & $50 \%(4)$ & $25 \%(4)$ \\
Medium and high sophistication in all three areas & $12.5 \%(1)$ & $44 \%(7)$ \\
Medium in all areas & $12.5 \%(1)$ & $6 \%(1)$ \\
High sophistication in all areas & 0 & $12.5 \%(2)$ \\
\hline $\mathrm{N}$ & 8 & 16 \\
\hline
\end{tabular}


DEVELPOING PSTS' ABILITY TO ATTEND, ANALYZE, AND RESPOND

Table 6

Relationship Between Attending, Analyzing, and Responding for All Participants

\begin{tabular}{|c|c|c|c|c|c|}
\hline \multicolumn{6}{|c|}{ Attending } \\
\hline & $\begin{array}{l}\text { Level of } \\
\text { sophistication }\end{array}$ & & Low & Medium & High \\
\hline \multirow{3}{*}{ Analyzing } & Low & Observed & 1 & 4 & 0 \\
\hline & Medium & Observed & 3 & 3 & 9 \\
\hline & High & Observed & 0 & 1 & 3 \\
\hline \multicolumn{6}{|c|}{$\mathrm{T}_{\mathrm{B}}=.387 p=.003$} \\
\hline \multicolumn{6}{|c|}{ Responding } \\
\hline & & & Low & Medium & High \\
\hline \multirow[t]{3}{*}{ Analyzing } & Low & Observed & 4 & 1 & 0 \\
\hline & Medium & Observed & 3 & 12 & 0 \\
\hline & High & Observed & 1 & 0 & 3 \\
\hline \multicolumn{6}{|c|}{$\mathrm{T}_{\mathrm{B}}=.572 p=.001$} \\
\hline \multicolumn{6}{|c|}{ Responding } \\
\hline & & & Low & Medium & High \\
\hline \multirow[t]{3}{*}{ Attending } & Low & Observed & 1 & 3 & 0 \\
\hline & Medium & Observed & 4 & 3 & 1 \\
\hline & High & Observed & 3 & 7 & 2 \\
\hline
\end{tabular}

